\title{
New Operation Strategy for a Grid-Connected Three-Phase Three-Level NPC qZS Inverter Based on Power Losses
}

\author{
Carlos Roncero-Clemente ${ }^{1,3}$, Enrique Romero-Cadaval ${ }^{1}$, Oleksandr Husev ${ }^{2}$, Joao Martins ${ }^{3}$ \\ ${ }^{1}$ Power Electrical and Electronic Systems (PE\&ES) Research Group, University of Extremadura, \\ Spain \\ ${ }^{2}$ Department of Electrical Engineering, Tallinn University of Technology, \\ Tallinn, Estonia \\ ${ }^{3}$ UNINOVA and Faculty of Sciences and Technology, University Nova de Lisboa, \\ Lisboa, Portugal \\ croncero@peandes.net
}

\begin{abstract}
This paper proposes a new operation strategy for a three-phase three-level neutral-point-clamped quasiimpedance source inverter in a grid-connected mode. The strategy is intended for any inverter based on impedance source networks where the shoot-through states allow a wider input operation range. This feature is commonly requested in photovoltaic applications due to variations in the level of irradiance. Converters of that family have different control variables or degrees of freedom that can be used to boost the input voltage. In the first step, focus was on possible control variables for the design of the control strategy to regulate the active/reactive power. We used a power losses analysis to determine the most suitable variables in each input voltage interval. Our detailed description for the design of the control strategy is based on the well-known relationship in an electrical system between $P-\delta$ and $Q-V$. Good performance of the full system was validated by simulations.
\end{abstract}

Index Terms-Distributed generation; impedance source inverter; power losses; grid-connected algorithms.

\section{INTRODUCTION}

Shortage of fossil fuels and the need for reduction of $\mathrm{CO}_{2}$ emissions, among other reasons, have resulted in increased use of inverter-based distributed generators (DGs) connected to the low-voltage distribution network (Fig. 1) [1]. Typically, they interact with renewable energy sources (RES), such as photovoltaic (PV) modules [2] and wind turbines [3]. To add here, they are present in any energy storage process [4].

According to long-term studies of the PV systems, a PV inverter has been used merely to inject power into the main grid with a unitary power factor [2]. Today, new trends and policies propose to integrate them as active and smart devices [5]. This philosophy contributes to the change from the traditional and linear power systems to the smartgrid and microgrid concepts [6]. In this way, inverters would be able

Manuscript received 8 October, 2015; accepted 2 April, 2016.

This research was funded by Nobel Grid project (European Union's Horizon 2020 under the grant agreement $n^{\circ}$ 646184). This research was cofunded by a grant PUT (PUT633) from Estonian Research Council. to contribute to the local voltage support, improve the power quality and give rise to flexibility and security of supply.

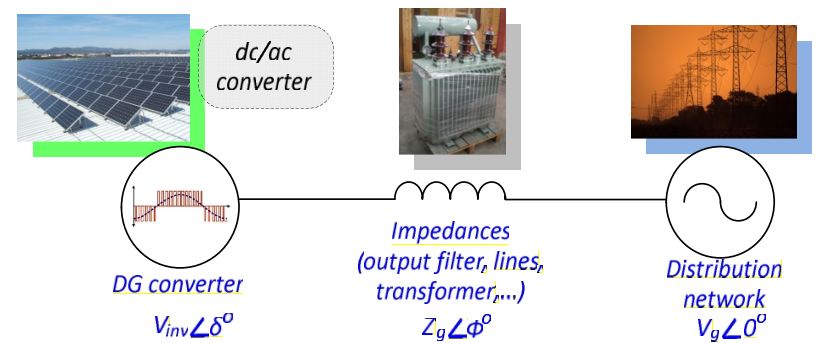

Fig. 1. Basic scheme of a PV DG connected to the low-voltage distribution network.

Concurrently, efforts in industry and research are targeted to cost reductions and enhanced performance of the energy conversion process, with a focus on the inverter topologies $\mathrm{PV}$ inverters are traditionally characterized by a two-stage conversion process composed of a dc-dc boost converter and a voltage source inverter. Some innovative ideas seem quite suitable for this application because they can step up the dc input voltage in a single power conversion stage by using impedance source network (ZSN), quasi impedance network (qZSN) or its derivations [7]-[9]. Among other advantages, this converter family allows the following: voltage boost/buck, extended range of operation, low cost and high efficiency, strong electromagnetic immunity, no need for dead time, minimum number of semiconductor devices, improved reliability and performance, and short-circuit protection. Furthermore, impedance networks have been integrated with multilevel bridges (ML) [10] to acquire their intrinsic advantages.

However, because of a relatively early stage, only few studies address grid-connected integration with closed loop control systems, which basically must provide coexistence of an operation strategy of the inverter, a maximum power point tracking (MPPT) algorithm, a dc-link voltage control method [11], and a special modulation technique to embed the shoot-through states into the normal ones [12].

This paper presents the design of a new operation strategy based on a grid-connected three-phase Three-Level Neutral- 
Point-Clamped quasi-Impedance Source Inverter (3L-NPCqZSI) [13] for active $(P)$ and reactive $(Q)$ power delivery into the main grid. As this topology provides new degrees of freedom that can be used in the operation strategy design, a power losses analysis was performed to select the variables that contribute to a higher performance of the converter in each operation range (depending on the input voltage). The proposed ideas were validated by a comprehensive simulation study in PSCAD/EMTDC.

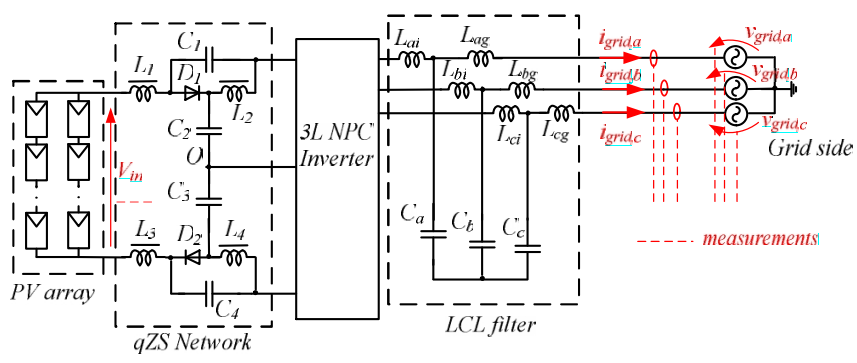

Fig. 2. Schematic circuit of the grid-connected three-phase 3L-NPC-qZSI. Case study.

\section{DESIGN OF THE GRID-CONNECTED OPERATION STRATEGY}

\section{A. Basis of the New Proposed Grid-Connected Control Strategy for a $3 L-N P C$-qZSI to regulate $P$ and $Q$}

A grid-connected operation strategy for the new family of converter topologies based on ZSN or qZSN together with ML bridges can be derived from traditional approaches. In this sense, in a balanced three-phase system, if $V_{\text {gen }}$ and $V_{g}$ are the RMS generator and the point of common coupling (PCC) voltages respectively, $P$ and $Q$ are given as [14]:

$$
\begin{gathered}
P=\frac{V_{g e n} V_{g}}{X_{g e n}} \sin \delta, \\
Q=\frac{V_{g}}{X_{g e n}}\left(V_{g e n} \cos \delta-V_{g}\right),
\end{gathered}
$$

where $\delta$ represents the angle between $V_{\text {gen }}$ and $V_{g}$ and $X_{g e n}$ is the impedance of the generator. Assuming that $\delta$ is small, (1) and (2) can be approximated by the first term of the Taylor series as:

$$
\begin{gathered}
P \approx \frac{V_{g e n} V_{g}}{X_{\text {gen }}} \delta, \\
Q \approx \frac{V_{g} V_{\text {gen }}-V_{g}^{2}}{X_{\text {gen }}} .
\end{gathered}
$$

These equations are widely used in traditional power systems to control high power synchronous generators where the manipulated variables for power regulation are $P(\delta)$ and $Q\left(V_{\text {gen }}-V_{g}\right)$. Analogy can be drawn between the previous equations and the equation that governs the RMS phase-toneutral output voltage of the new inverter [13]

$$
V_{i n v}=M \frac{V_{d c}}{2 \sqrt{2}}=M \frac{V_{i n}}{2 \sqrt{2}\left(1-2 D_{s}\right)},
$$

where $M$ is the modulation index, $V_{d c}$ represents the dc-link voltage, $V_{\text {in }}$ is the input voltage, and $D_{s}$ is the shoot-through duty cycle. Therefore, to modify $V_{i n v}$ (buck or boost) in relation to $V_{i n}$, we have two control variables ( $M$ and $D_{s}$ ) based on a simple boost control (SBC) for a modulation technique [15] where $D_{s}$ has to be in a range of $M \leq 1-D_{s}$. Finally, combining (3) and (4) for the particular case of $3 \mathrm{~L}$ NPC-qZSI (5), we obtain the following relationships between the control variables involved:

$$
\begin{gathered}
P=P(\delta), \\
Q=Q\left(M, D_{s}\right) .
\end{gathered}
$$

In addition, the third harmonic injection is commonly used in a three-phase inverter to increase the linear range of $M$ and in consequence, the voltage gain range as well. According to [16], the maximum $M$ is approximately equal to 1.15 when $1 / 6(\approx 19 \%)$ of the third harmonic is injected.

Based on the aforementioned equations, thanks to the shoot-through states and by injecting the third harmonic in the reference signal, the buck-boost possibilities are larger than in a conventional inverter. $V_{\text {in }}$ can be step up or down by regulating $M, D_{s}$ and/or the percentage of $3^{r d}$ harmonic injection. Taking into account the well-known electrical relationships between $\left(P-\delta\right.$ and $Q-V_{\text {gen }}\left(\right.$ or $\left.\left.V_{i n v}\right)\right)$, we will assume that the degrees of freedom to manipulate the delivery of $P$ and $Q$ by the inverter are:

$$
\begin{gathered}
P=P(\delta), \\
Q=Q\left(M, D_{S}, \% 3^{r d} \text { injection }\right) .
\end{gathered}
$$

It should be highlighted that in PV applications, the reference of the active power is usually obtained from the MPPT algorithm, to extract the maximum amount of power available in the PV array [17]. Several approaches in the literature [1] can be used to generate the reference of $Q$. In our case, the maximum capability of the inverter $\left(S_{N}\right.$, defined by the rated current of semiconductors) is considered, and the equation for the generation of the reference of $Q$ is given by that in Fig. 3 .

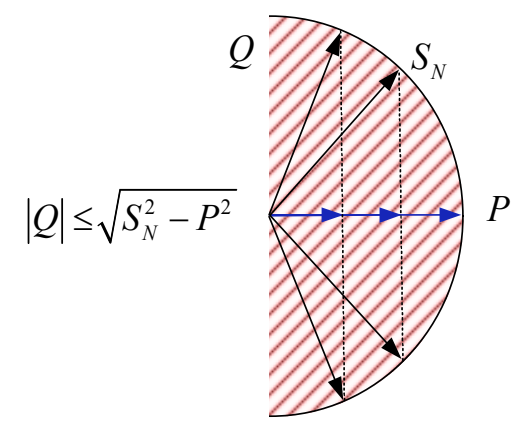

Fig. 3. PV inverter regulation capability.

\section{B. Design of the Grid-Connected Control Strategy Based on Power Losses}

In steady state grid-connected conditions, to control $P$ and $Q$ flows successfully with a traditional single-stage 3-phase inverter operating with a sinusoidal pulse-width-modulation (SPWM) (only buck mode is allowed), $V_{\text {in }}$ higher than $650 \mathrm{~V}$ 
is required, i.e., to generate $230 \mathrm{~V}$ RMS phase-to-neutral voltage. This requirement changes in the case of single stage buck-boost inverters based on ZSN like the three-phase 3LNPC-qZSI. Due to the shoot-through states and the third harmonic injection, the buck-boost operation range depending on the input voltage is wider there. We can distinguish three different regions (depending on the input voltage) since the maximum $M$ when a $1 / 6$ of the $3^{r d}$ harmonic is injected is 1.15 . The threshold where the third harmonic is required is $565 \mathrm{~V}$ of $V_{i n}$. Different situations that can be presented depending on the input voltage are summarized in Table I.

TABLE I. POSSIBLE CASES FOR BUCK-BOOST CONVERSION IN GRID CONNECTION IN THE 3L-NPC-QZSI.

\begin{tabular}{|c|c|c|c|c|}
\hline$V_{\text {in }}$ & $\begin{array}{c}\text { Working } \\
\text { mode }\end{array}$ & $M$ & $\% 3^{\text {rd }}$ harm. & $D_{s}$ \\
\hline$V_{\text {in }}>650 \mathrm{~V}$ & $\begin{array}{l}\text { Buck } \\
\text { mode }\end{array}$ & $\begin{array}{c}M<\mathbf{1} \\
M<1.15 \\
M<1 \\
M<1.15\end{array}$ & $\begin{array}{c}\mathbf{0} \\
0<\%<19 \\
0 \\
0<\%<19 \\
\end{array}$ & $\begin{array}{c}\mathbf{0} \\
0 \\
0<D_{s}<1-M \\
0<\mathrm{D}_{\mathrm{s}}<1-M\end{array}$ \\
\hline $\begin{array}{l}650 V>V_{\text {in }} \\
V_{\text {in }}>565 V\end{array}$ & $\begin{array}{l}\text { Boost } \\
\text { mode }\end{array}$ & $\begin{array}{c}M<\mathbf{1 . 1 5} \\
M<1 \\
M<1.15\end{array}$ & $\begin{array}{c}0<\%<19 \\
0 \\
0<\%<19\end{array}$ & $\begin{array}{c}\mathbf{0} \\
0<D_{s}<1-M \\
0<D_{s}<1-M\end{array}$ \\
\hline$V_{\text {in }}<565 V$ & $\begin{array}{l}\text { Boost } \\
\text { mode }\end{array}$ & $\begin{array}{c}M<\mathbf{1 . 1 5} \\
M<1\end{array}$ & $\begin{array}{c}\%=19 \\
0\end{array}$ & $\begin{array}{l}\mathbf{0}<\mathbf{D}_{\mathbf{s}}<\mathbf{1}-\boldsymbol{M} \\
0<D_{s}<1-M\end{array}$ \\
\hline
\end{tabular}

To evaluate the working modes within all possible combinations between $M, D_{s}$ and $\% 3^{\text {rd }}$ harmonic with variable input voltage, the criteria of power losses were selected according to Table I. The full system [11], [13] was modelled in PSCAD/EMTDC with the values of the real parameters, and tested by varying the input voltage while maintaining $230 \mathrm{~V}$ RMS at the output, paying attention to the global inverter efficiency (including switching and conduction losses as well as those in passive elements) at nominal power $(5 \mathrm{~kW})$. The obtained results in each test are presented in Fig. 4.

Starting from $V_{\text {in }}>650 \mathrm{~V}$, there are several possibilities to produce the desired output voltage. The first case is working in a simple buck mode $\left(M<1, \% 3^{r d} h .=0, D_{s}=0\right)$, with the efficiency represented by a green line. In the second option $\left(M<1.15, \% 3^{r d} h .=19 \%, D_{s}=0\right)$, the efficiency is represented with a magenta dotted line. Possible combinations in between $\left(M<1.15\right.$ and $\left.\% 3^{\text {rd }} h .<19 \%\right)$ are represented in the area between both lines. The third case considered is at $D_{s}=0.065$ (value that produces a voltage gain of $15 \%), \% 3^{r d} h .=0$ and $M \leq 1-D_{s}$, with the efficiency represented by a red dotted line. We can see a significant reduction of the efficiency due to the application of the shoot-through states. Efficiencies of the combinations between $3^{\text {rd }} h$. $<19 \%, D_{s}=0.065$ and $M<1-D_{s}$ are represented between both lines. Down the red dotted line, $D_{s}$ $>0.065, \% 3^{r d} h .=0$ and $M<1-D_{s}$, the efficiency decreases.

In the band between $565 \mathrm{~V}$ (minimum value of $V_{\text {in }}$ to produce $230 \mathrm{~V}$ RMS by injecting $19 \%$ of $3^{\text {rd }} h$.) to $650 \mathrm{~V}$, different possibilities are revealed. The first case is considering $\left(D_{s}=0,0<\% 3^{\text {rd }} h .<19\right.$ and $\left.1<M<1.15\right)$, with the efficiency represented by a green line. The other case is (in blue solid line) composed by $\% 3^{r d}=0,0<D_{s}<$ 0.116 (equivalent value to boost the input voltage from $565 \mathrm{~V}$ to $650 \mathrm{~V}$ ), which matches with the worst efficiency in this interval. The efficiency of possible combinations is the enclosed area between both lines.

In the interval from $565 \mathrm{~V}$, two ways of operation are available. In the first mode, $D_{s}$ starting from the point $\left(\% 3^{\text {rd }}\right.$ $h .=19$ and $M=1.15$ ) is modified (green line). The second mode is by controlling the $3^{r d}$ harmonic injection, maintaining $0.19, D_{s}=0.116$ (black line). Both lines converge when the input voltage is $491 \mathrm{~V}\left(D_{s}=0.116, \% 3^{\text {rd }}\right.$ $h .=0.19)$.

In the last interval $\left(V_{\text {in }}<491 \mathrm{~V}\right)$, the best solution from the efficiency point of view is to inject the maximum value of $3^{r d}$ harmonic $(19 \%)$ and increase the $D_{s}$ from 0.116 . It is also represented as a green line. Therefore, the best operation is achieved by using the parameters in bold in Table I. Those parameters along the $\delta$ angle of the reference signal will be the control variables of the proposed control strategy to regulate the active and reactive power delivery into the grid by the three-phase 3L-NPC-qZSI.

\section{Proposed OPERATION STRATEGY}

Based on the ideas presented in the previous section, to regulate $P$ and $Q$, we selected the following control variables:

$$
\begin{gathered}
P=P(\delta), \\
Q=Q(M) \text { if } V_{I N}>650 \mathrm{~V}, \\
Q=Q(M) \text { with } 3^{r d} h \text {. injection if } 565 V<V_{I N}<650 \mathrm{~V}, \\
Q=Q\left(D_{S}\right) \text { with } 3^{r d} h . \text { injection if } V_{I N}<565 \mathrm{~V} .
\end{gathered}
$$

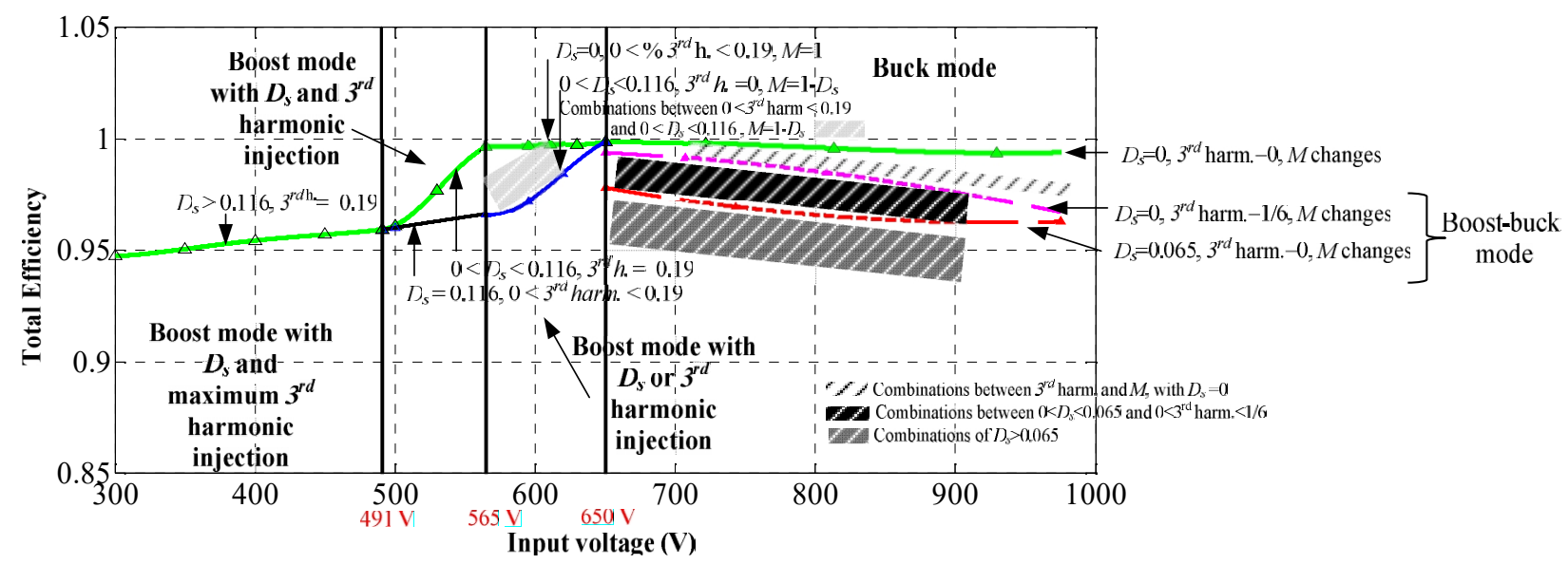

Fig. 4. Efficiency estimation depending on the working mode. 
Hence, by the simple integral (I) controllers, references of $P$ and $Q$ could be properly tracked, regulating the defined control variables. Due to the power control loops present coupling according to (6) and (7), one control loop has to be faster than the other one. Each integral controller is tuned manually by a trial and error method.

Fig. 5 shows the implementation scheme of the proposed control strategy. As shown in the sketch, depending on the value of the input voltage, one or others control variables are involved in the reactive power control loop. The adjusted values of $(\delta, M, \ldots)$ will compose the reference signal as the input of the SPWM block (called 3-phase generator with $\mathrm{SBC}$ ). The shapes of the reference signals in each working mode are presented in Fig. 6.

In order to synchronize with the main grid, a feedforward loop with the phase of the grid voltage was added to the output of the integral controller that regulates the active power. It avoids undesired transients during the grid inverter connection.

\section{Simulation StUdy}

To verify the proposed strategy, a comprehensive simulation study was performed in PSCAD simulation tool. Table II presents all the parameters used in each of the three simulation studies in [11] and [13], one per interval of $V_{i n}$. Basically, the tests consist in two different reference steps, as in active $\left(P_{r e f}\right)$ and reactive reference $\left(Q_{r e f}\right)$ power to check if all the control variables and electrical magnitudes are under the expected values. $P_{\text {ref }}$ changes from 2 to $3 \mathrm{~kW}$ at second 1.5 (limit between zone A and B) and $Q_{\text {ref }}$ changes from 0 to $0.5 \mathrm{kVAr}$ in second 3 (zone $\mathrm{C}$ ).

\section{A. Case 1. $V_{\text {in }}>650 \mathrm{~V}$}

In this case, the converter has to work in buck mode by using the variable in bold in the first row of Table I. Hence, the reference signal will have the shape of Fig. 6 a).

Fig. 7 shows the main obtained waveforms: a) measured active and reactive power, b) evolution of $\delta$, c) evolution of
$M$, d) grid currents and voltages, e) dc-link voltage, and f) input current and voltage.

\section{B. Case 2. $650 \mathrm{~V}>V_{\text {in }}>565 \mathrm{~V}$}

In this case, the converter has to work in boost mode by injecting $19 \%$ of $3^{\text {rd }}$ harmonic according to Table I. In this case, the reference signal will have the shape of Fig. 6 b).

Figure 8 shows the main obtained waveforms and control variable evolution as in the previous case: a) measured active and reactive power, b) evolution of $\delta$, c) evolution of $M, \mathrm{~d})$ grid currents and voltages, e) dc-link voltage, and f) input current and voltage. The references are tracking successfully again.

TABLE II. SIMULATION PARAMETERS

\begin{tabular}{|c|c|c|c|}
\hline Parameter & Unit & Element & Value \\
\hline Inductors $L_{1}, L_{2}, L_{3}$ and $L_{4}$ & $(\mathrm{mH})$ & \multirow{3}{*}{ qZ network } & 0.9 \\
\hline $\begin{array}{c}\text { Capacitors } \\
C_{1}, C_{2}, C_{3} \text { and } C_{4}\end{array}$ & $(\mu \mathrm{F})$ & & 200 \\
\hline $\mathrm{T}$ & $\left({ }^{\circ} \mathrm{C}\right)$ & & 25 \\
\hline$L_{f I}$ & $(\mathrm{mH})$ & \multirow{3}{*}{ Output filter } & 1.2 \\
\hline$L_{f 2}$ & $(\mathrm{mH})$ & & 0.5 \\
\hline$C_{f}$ & $(\mu \mathrm{F})$ & & 0.11 \\
\hline RMS Voltage: $U^{L-L}$ & $(\mathrm{~V})$ & \multirow{3}{*}{$\begin{array}{c}\text { Grid } \\
\text { parameters }\end{array}$} & 400 \\
\hline Short-circuit power: & $\%$ & & 2MVA \\
\hline Frequency & $\mathrm{Hz}$ & & 50 \\
\hline Nominal power: $S_{n}$ & $\mathrm{kVA}$ & \multirow{5}{*}{$\begin{array}{c}\text { Power } \\
\text { transformer }\end{array}$} & $50 \mathrm{kVA}$ \\
\hline Nominal winding voltages & $\mathrm{V}$ & & $400 / 400$ \\
\hline $\begin{array}{l}\text { Positive sequence } \\
\text { reactance: } X_{d}\end{array}$ & p.u & & $0.04 \mathrm{pu}$ \\
\hline Open circuit losses & & & $0.003 \mathrm{pu}$ \\
\hline Copper losses & & & $0.005 \mathrm{pu}$ \\
\hline$C_{\text {upper }}$ and $C_{\text {lower }}$ & $(\mathrm{kHz})$ & \multirow{3}{*}{$\begin{array}{c}\text { General } \\
\text { parameter }\end{array}$} & 50 \\
\hline$C s-t$ & $(\mathrm{kHz})$ & & 100 \\
\hline Simulation step & $(\mu \mathrm{s})$ & & $0.2\left(50 f_{s w}\right)$ \\
\hline
\end{tabular}

\section{Case 3. $V_{\text {in }}<565 \mathrm{~V}$}

In this new situation, the converter has to work in boost mode by injecting $19 \%$ of $3^{r d}$ harmonic and by means of $D_{s}$. In this case, the reference signal has the shape of Fig. 6(c).

Figure 9 shows the main obtained waveforms.

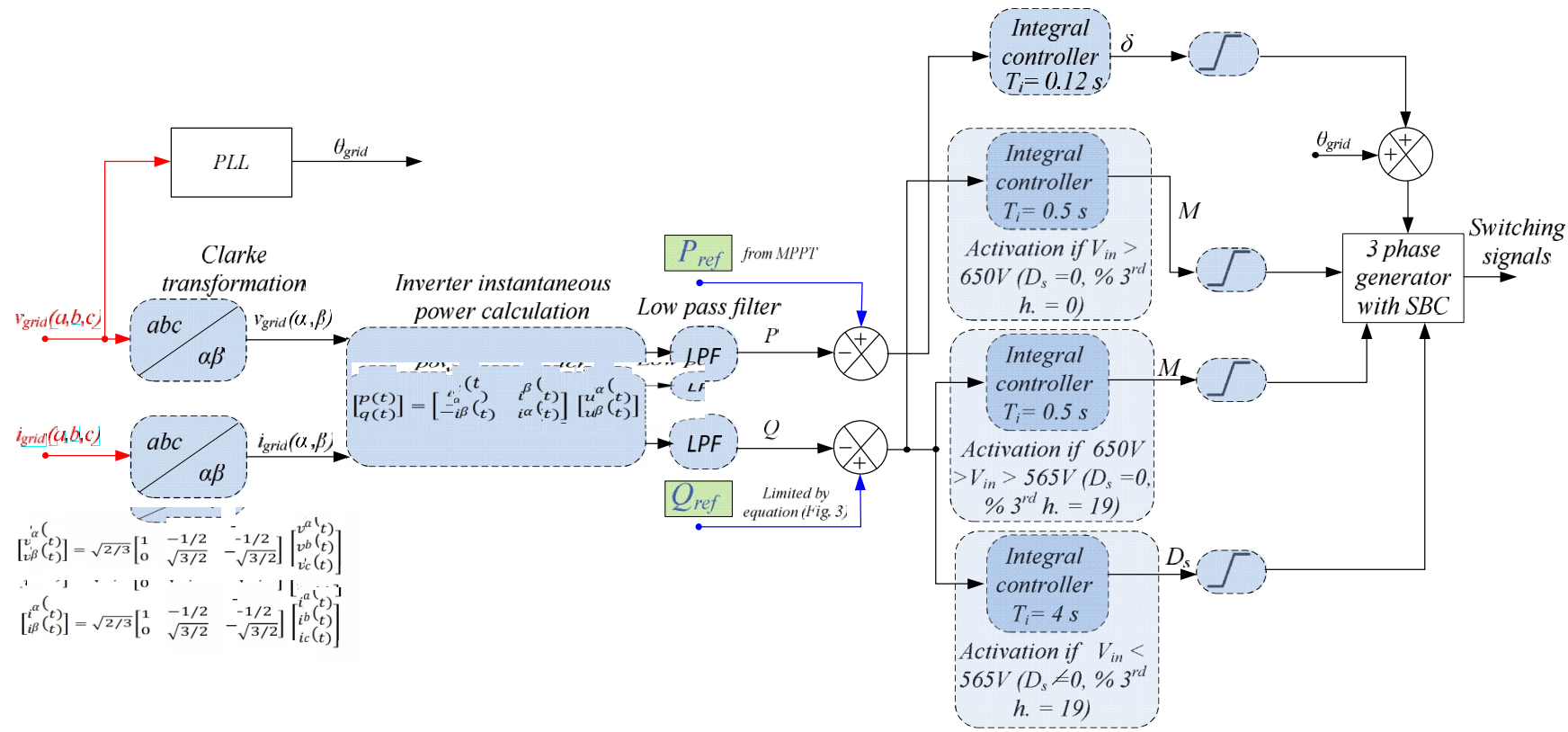

Fig. 5. Main diagram blocks of the proposed grid-connected control strategy. 


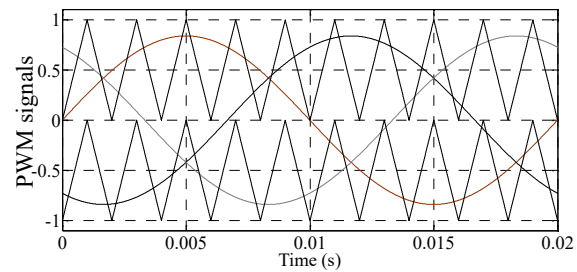

(a)

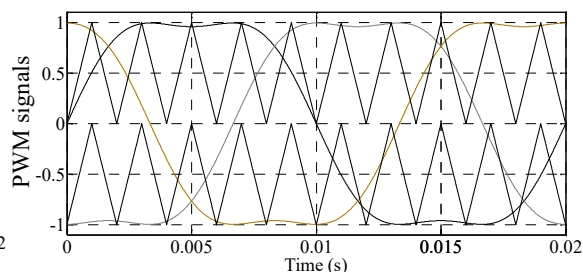

(b)

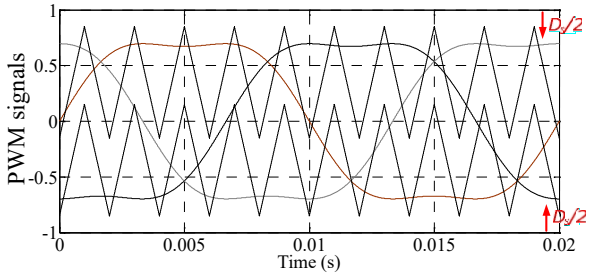

(c)

Fig. 6. Shape of the reference signals in each interval depending on the input voltage: a) $V_{\text {in }}>650 \mathrm{~V}$; b) $650 \mathrm{~V}>V_{\text {in }}>565 \mathrm{~V}$; c) $V_{\text {in }}<565 \mathrm{~V}$.

\section{DISCUSSION}

In the first interval $\left(V_{\text {in }}>650 \mathrm{~V}\right)$, the input voltage boost is not required. By manipulating the angle $\delta$ (Fig. 7(b)) and the $M$ (Fig. 7(c)), the references of active and reactive power are tracked successfully (Fig. 7(a)). In the same picture, a coupling between both power control loops is appreciated. It is due to both $\delta$ and $M$ involved in the main equations of $P$ and $Q((1)$ and (2)). This effect is more significant in the low-voltage distribution network where the coefficient $R / X$ becomes higher and the assumptions adopted in (3) and (4) lose applicability [18]. This coupling may be mitigated by using control techniques based on a $d-q$ rotating reference frame [11]. Finally, the waveforms of grid voltage and current in region 3 (Fig. 7(d)), where the inverter is injecting both $P$ and $Q$, demonstrate a good quality, with a low value of total harmonic distortion (THD $<1.5 \%$ ).

In the second interval $\left(650 \mathrm{~V}>V_{\text {in }}>565 \mathrm{~V}\right)$, it is required to boost the input voltage for the grid-connection. Resulting from the power losses study, it is better to use the injection of $3^{\text {rd }}$ harmonic than the shoot-through states. The results revealed in Fig. 8 are very similar to those of the previous case.

In the last interval $\left(V_{\text {in }}<565 \mathrm{~V}\right)$, the $3^{\text {rd }}$ harmonic injection is not enough to boost the input voltage. Hence, the injected power would not be regulated. $Q$ is tracked by adjusting the $D s$ in this case, allowing a higher input voltage boost, as expenses of higher power losses, as section II $B$ ) demonstrates. Small changes in $D_{s}$ (Fig. 9(c)) produce significant variations [19] in the voltage boost, hence also in reactive power. This effect is transferred to the output side [19] where the quality of the output current and voltage (Fig. 9(d)) is lower than in the previous cases (THD of the voltage around $4 \%$ ). For this reason, the integral controller dedicated to $D_{s}$ is tuned to produce a slower response.

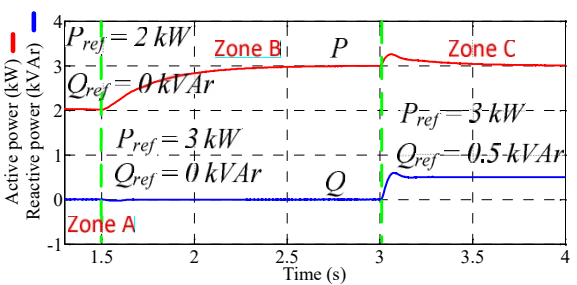

(d)

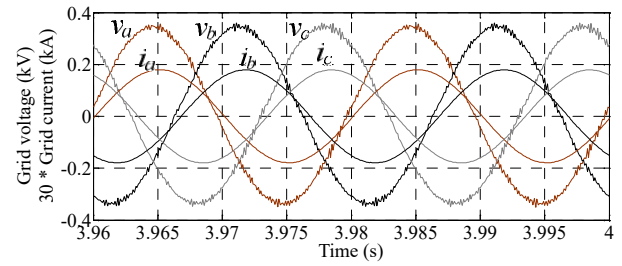

(d)

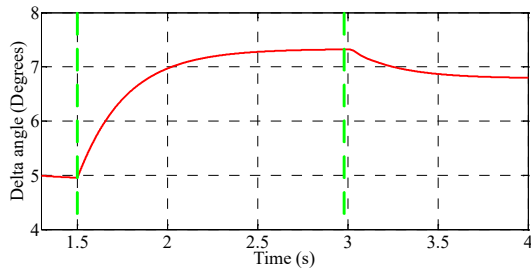

(b)

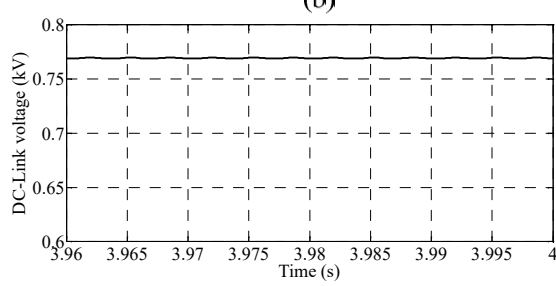

(e)

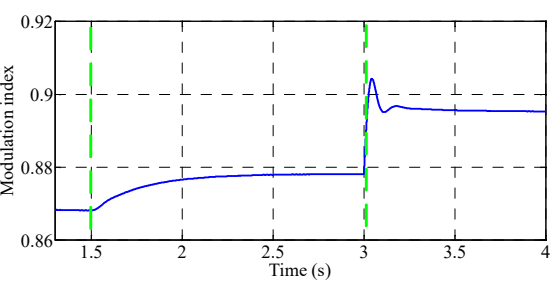

(c)

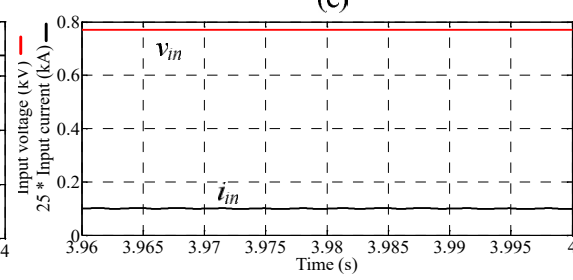

(f)

Fig. 7. Main waveforms in case $1\left(V_{\text {in }}>650 \mathrm{~V}\right)$ : a) Measured active and reactive power; b) Evolution of $\delta$; c) Evolution of $M$; d) Grid voltage and injected current in Zone C; e) dc-link voltage; f) Input current and voltage.

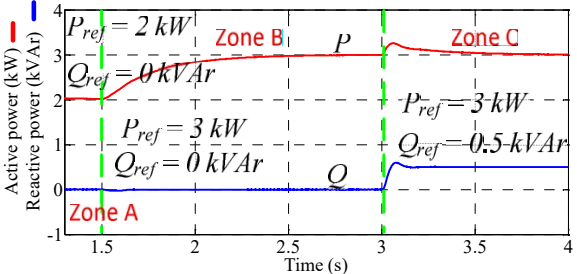

(a)

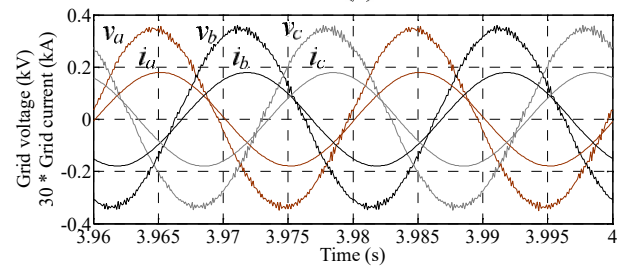

(d)

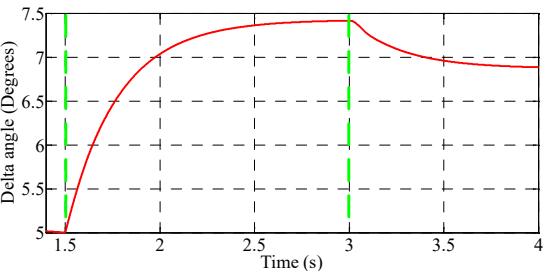

(b)

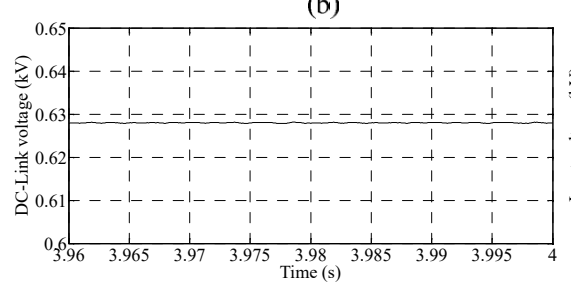

(e)

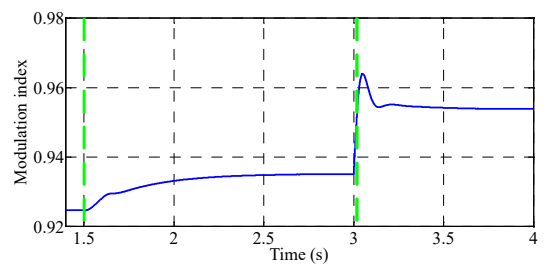

(c)

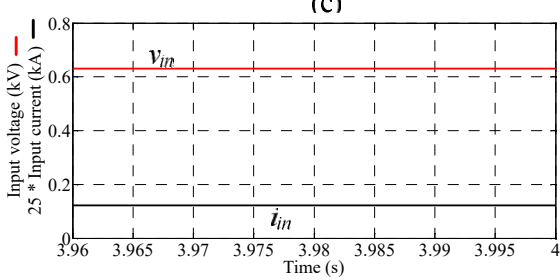

(f)

Fig. 8. Main waveforms in case $2\left(650 \mathrm{~V}>V_{\text {in }}>565 \mathrm{~V}\right)$ : a) Measured active and reactive power; b) Evolution of $\delta$; c) Evolution of $M$; d) Grid voltage and injected current in Zone C; e) dc-link voltage; f) Input current and voltage. 


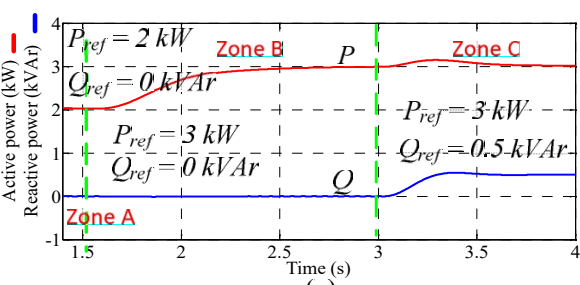

(a)

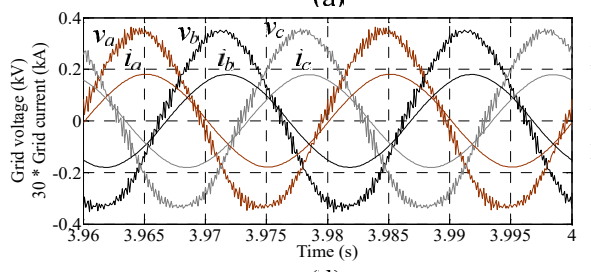

(d)

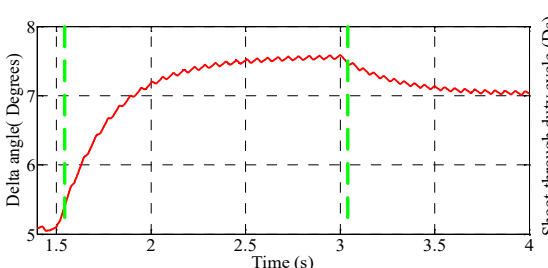

(b)

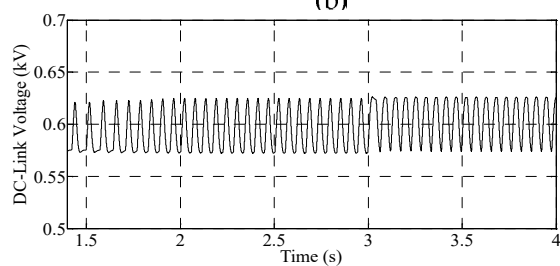

(e)

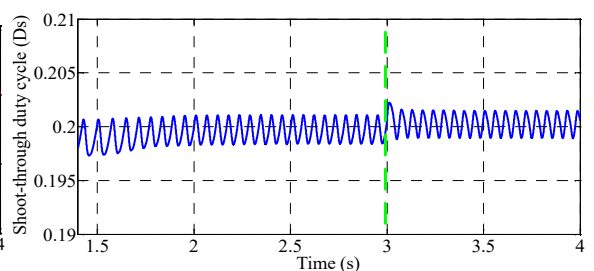

(c)

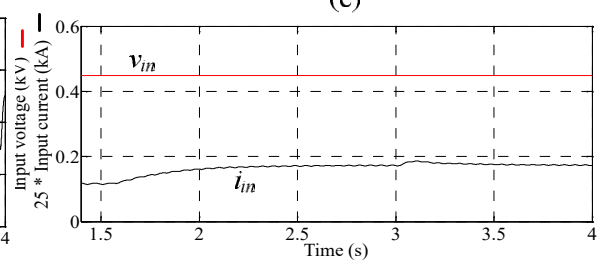

(f)

Fig. 9. Main waveforms in case $3\left(V_{\text {in }}<565 \mathrm{~V}\right)$. a) Measured active and reactive power; b) Evolution of $\delta$; c) Evolution of $D_{s}$; d) Grid voltage and injected current in Zone $C$; e) dc-link voltage. f) Input current and voltage.

\section{CONCLUSIONS}

This paper has presented the design of a new operation strategy for a grid-connected three-phase 3L-NPC-qZSI to regulate the injected active and reactive power. The strategy along with the closed loop controls can be used for any inverter based on ZSN or its derivations. The main feature is that they can boost the input voltage by means of the insertion of the shoot-through states. As new control variables (or degrees of freedom) are available in this family of power converters, a study of power losses was developed to determine the variables that seem more suitable to be manipulated depending on the required voltage boost. Once these variables have been selected, the control strategy can be designed and implemented. The simulation results obtained validated the proposed ideas and the expected behaviour of the full system.

\section{REFERENCES}

[1] K. Turitsyn, P. Sulc, S. Backhaus, M. Chertkov, "Options for control of reactive power by distributed photovoltaic generators", in Proc. IEEE, 2011, vol. 99, no. 6, pp. 1063-1073. [Online]. Available: http://dx.doi.org/10.1109/JPROC.2011.2116750

[2] E. Romero-Cadaval, G. Spagnoulo, L. Garcia-Franquelo, C. RamosPaja, T. Suntio, W. Xiao, "Grid-connected photovoltaic generation plants: Components and Operation", IEEE Ind. Electr. Mag., vol. 7, no. 3, pp. 6-20, 2013. [Online]. Available: http://dx.doi.org/ 10.1109/MIE.2013.2264540

[3] F. Blaabjerg, R. Teodorescu, M. Liserre, AV. Timbus, "Overview of control and grid synchronization for distributed power generation systems", IEEE Trans. Ind. Electron., vol. 53, no. 5, pp. 1398-1409, 2006. [Online]. Available: http://dx.doi.org/10.1109/TIE. 2006.881997

[4] K. C. Divya, J. Ostergaard, "Battery energy storage technology for power systems-an overview", Electric Power Systems Research, vol. 79, no. 4, pp. 511-520, 2009. [Online]. Available: http://dx.doi.org/10.1016/j.epsr.2008.09.017

[5] E. Romero-Cadaval, V. Minambres-Marcos, A. Moreno-Munoz, R. Real-Calvo, J. Gonzalez de la Rosa, J. M. Sierra-Fernandez, "Active functions implementation in smart inverters for distributed energy resources", in $8^{\text {th }}$ Int. Conf.-Workshop. Proc. IEEE Compatibility and Power Electronics (CPE 2013), Ljubljana Slovenia, 2013, pp. 52-57. [Online]. Available: http://dx.doi.org/ 10.1109/CPE.2013.6601128

[6] J. M. Guerrero, J. C. Vasquez, J. Matas, L. G de Vicuna, M. Castilla, "Hierarchical control of droop-controlled AC and DC microgrids-a general approach toward standardization", IEEE Trans. Industrial Electronics, vol. 58, no. 1, pp. 158-172, 2011. [Online]. Available: http://dx.doi.org/10.1109/TIE.2010.2066534

F. Z. Peng, "Z-Source inverter", IEEE Trans. Ind. Appl., vol. 39, no. 2, pp. 504-510, 2003. [Online]. Available: http://dx.doi.org/
10.1109/TIA.2003.808920

[8] J. Anderson, F. Z. Peng, "Four quasi-Z-Source inverters", IEEE Power Electronics Specialists Conf., (PESC 2008), pp. 2743-2749, 2008. [Online]. Available: http://dx.doi.org/10.1109/PESC.2008. 4592360

[9] Y. P. Siwakoti, Fang Zheng Peng; F. Blaabjerg, Poh Chiang Loh, G. E. Town, "Impedance-source networks for electric power conversion part i: a topological review", IEEE Trans. Power Electronics, vol. 30, no. 2 , pp. $699-716,2015$. [Online]. Available: http://dx.doi.org/ 10.1109/TPEL.2014.2313746

[10] L. G. Franquelo, J. Rodriguez, J. I. Leon, S. Kauro, R. Portillo, M. A. M. Prats, "The age of multi-level converters arrives", IEEE Industrial Electronic Magazine, vol. 49, pp. 28-39, 2008. [Online]. Available: http://dx.doi.org/10.1109/MIE.2008.923519

[11] C. Roncero-Clemente, O. Husev, E. Romero-Cadaval, D. Vinnikov, M. I. Milanes-Montero, "Operation strategy and shoot-through indirect control method for three-phase Z-source inverters", in IEEE $5^{\text {th }}$ Int. Conf. Power Engineering, Energy and Electrical Drives (POWERENG), 2015, pp. 576-581. [Online]. Available: http://dx.doi.org/10.1109/PowerEng.2015.7266380

[12] C. Roncero-Clemente, O. Husev, T. Jalakas, E. Romero-Cadaval, J. Zakis, V. Minambres-Marcos, "PWM for single-phase multilevel impedance-source inverter with balanced power losses", Elektronika ir Elektrotechnika, vol. 20, no. 6, pp. 71-76, 2014. [Online]. Available: $\mathrm{http}: / /$ dx.doi.org/10.5755/j01.eee.20.6.7270

[13] O. Husev, C. Roncero-Clemente, E. Romero-Cadaval, D. Vinnikov, T. Jalakas, "Three-level three-phase quasi-Z-source neutral-pointclamped inverter with novel modulation technique for photovoltaic application", Electric Power Systems Research, vol. 130, pp. 10-21, 2016. [Online]. Available: http://dx.doi.org/10.1016/j.epsr 2015.08.018

[14] S. Adhikari, L. Fangxing, "Coordinated V-f and P-Q control of solar photovoltaic generators with MPPT and battery storage in microgrids", IEEE Trans. Smart Grid, vol. 5, no. 3, pp. 1270-1281, 2014. [Online]. Available: http://dx.doi.org/10.1109/TSG.2014. 2301157

[15] H. Rostami, D. A. Khaburi, "Voltage gain comparison of different control methods of the Z-source inverter", Int. Conf. Electrical and Electronics Engineering (ELECO), 2009. pp. 268-272, 2009.

[16] G. Buja, G. Indri, "Improvement of pulse width modulation techniques", Archiv fur Elektrotechnik, vol. 57, pp. 281-289, 1975. [Online]. Available: http://dx.doi.org/10.1007/BF01476709

[17] T. Esram, P. L. Chapman, "Comparison of photovoltaic array maximum power point tracking techniques", IEEE Trans. Energy Conversion, vol. 22, no. 2, pp. 439-449, 2007. [Online]. Available: http://dx.doi.org/10.1109/TEC.2006.874230

[18] E. Demirok, D. Sera, R. Teodorescu, P. Rodriguez, U. Borup, "Evaluation of the voltage support strategies for the low voltage grid connected PV generators", IEEE Energy Conversion Congress and Exposition (ECCE), 2010, pp. 710-717. [Online]. Available: http://dx.doi.org/10.1109/ECCE.2010.5617937

[19] X. Ding, Z. Qian, S. Yang, B. Cui, F. Peng, "A direct peak DC-link boost voltage control strategy in Z-source inverter", in Conf. Proc. IEEE Applied Power Electronics (APEC), 2007, pp. 648-653. [Online]. Available: http://dx.doi.org/10.1109/APEX.2007.357583 